\title{
Embriogênese somática e regeneração de plantas a partir de embrião maduro de aveia(1)
}

Caren Regina Cavichioli Lamb(2), Sandra Cristina Kothe Milach ${ }^{(2)}$, Giancarlo Pasquali(3) e Raquel Santiago Barro(2)

Resumo - Calo embriogênico tem sido o tecido-alvo mais utilizado para transformação genética de cereais. O objetivo deste trabalho foi investigar o estabelecimento de calos embriogênicos e a regeneração de plantas in vitro a partir de embriões maduros de genótipos de aveia (Avena sativa L.). Embriões maduros foram retirados das sementes e colocados em meio MS (Murashige \& Skoog), contendo $30,0 \mathrm{~g} \mathrm{~L}^{-1}$ de sacarose e $2,0 \mathrm{mg} \mathrm{L}^{-1}$ de ácido 2,4-diclorofenoxiacético (2,4-D). Após o período de indução de calos, agregados embriogênicos foram isolados e subcultivados a cada 21 dias para meio fresco. Os calos embriogênicos foram então transferidos para meio de indução de parte aérea, e, na seqüência, as partes aéreas foram transferidas para meio de indução de raízes. Houve diferenças entre genótipos quanto à capacidade de embriogênese somática e regeneração de plantas in vitro a partir de embrião maduro. Este explante permitiu a indução de calos embriogênicos, que se multiplicaram, e que regeneraram in vitro um grande número de plantas de genótipos como UFRGS 7 e UFRGS 19, o que o faz passível de ser utilizado na transformação genética da aveia

Termos para indexação: Avena sativa, cultura de embrião, cultura in vitro, desenvolvimento embrionário, cereais.

\section{Somatic embryogenesis and plant regeneration derived from mature embryos of oat}

\begin{abstract}
Embryogenic callus has been the most used target tissue for cereal genetic transformation. Therefore, the objective of this study was to investigate the establishment of embryogenic calli and the in vitro plant regeneration from mature embryos of oat genotypes (Avena sativa L.). Mature embryos were taken out of the seeds and placed on a culture medium MS (Murashige \& Skoog), containing $30,0 \mathrm{mg} \mathrm{L}^{-1}$ of sucrose and $2,0 \mathrm{mg} \mathrm{L}^{-1}$ of 2,4-dichlorophenoxyacetic acid (2,4-D). From the induction period, embryogenic aggregates were isolated and subcultivated each 21 days into a fresh medium. After this period, embryogenic calli were transferred to a medium for shoot regeneration. Subsequently, the shoot was transferred to a medium for root induction. There was variability among genotypes for somatic embryogenesis and in vitro plant regeneration from mature embryos. This explant allowed the induction of calli with ability to multiply and regenerate high number of plants from genotypes as UFRGS 7 and UFRGS 19, what makes it capable for oat genetic transformation
\end{abstract}

Index terms: Avena sativa, embryo culture, in vitro culture, embryonic development, cereals.

(1) Aceito para publicação em 5 de março de 2001.

Extraído da Dissertação de Mestrado apresentada pelo primeiro autor à Universidade Federal do Rio Grande do Sul (UFRGS), Porto Alegre, RS.

Financiado pelo CNPq e pela Fapergs.

(2) UFRGS, Fac. de Agronomia, Dep. de Plantas de Lavoura, Caixa Postal 776, CEP 90501-970 Porto Alegre, RS. E-mail: milach@vortex.ufrgs.br

(3) UFRGS, Dep. de Biotecnologia.

E-mail: pasquali@dna.cbiot.ufrgs.br

\section{Introdução}

Os sistemas de cultivo in vitro, utilizados em aveia (Avena sativa $\mathrm{L}$.), são fortemente dependentes do genótipo (Bregitzer et al., 1995), o que limita o seu uso para a transformação genética. A escolha de um sistema que permita a regeneração in vitro de genótipos de interesse é fundamental para obtenção de plantas transgênicas férteis em aveia (Somers et al., 1996; Handel et al., 1997). 
A regeneração de plantas de aveia in vitro foi primeiramente obtida por Carter et al. (1967), com culturas iniciadas de sementes maduras. Anos mais tarde, foi relatada a iniciação de calos e regeneração de plantas de aveia a partir de embriões imaturos (Cummings et al., 1976; Rines \& McCoy, 1981). Contudo, foi apenas recentemente que a capacidade de regeneração in vitro a partir desse explante foi determinada em genótipos brasileiros de aveia, por Bered et al. (1996, 1998). Esses autores identificaram variabilidade entre genótipos em indução de calos embriogênicos e em regeneração de plantas, tendo UFRGS 7 se destacado no cultivo in vitro.

Os calos embriogênicos obtidos de embrião imaturo foram caracterizados morfologicamente por Bregitzer et al. (1989). Segundo esses autores, este tipo de calo é estabelecido em duas etapas: em seu estádio inicial, consiste de células vacuoladas não regeneráveis, e na segunda etapa, os agregados embriogênicos são selecionados e subcultivados, a fim de obter embriogênese somática.

Apesar da capacidade dos embriões imaturos para iniciação de calos embriogênicos, a obtenção desses explantes requer o desenvolvimento de plantas em condições ótimas de cultivo. Os embriões devem ser retirados de 12 até 18 dias após a antese, o que limita a sua disponibilidade e leva no mínimo 12 semanas para a iniciação de calos (Torbert et al., 1998). O desenvolvimento destas plantas é caro, e o isolamento de embriões é laborioso, dado o grande número de embriões que devem ser retirados. Além disso, o tempo necessário para estabelecer culturas de calos embriogênicos desse explante é demasiado longo, o que pode levar à redução da capacidade de regeneração e da fertilidade das plantas obtidas. Isto, segundo Torbert et al. (1998), tem dificultado a regeneração, e levado à obtenção de plantas transgênicas inférteis, em aveia.

Para minimizar esses problemas, foram utilizados calos embriogênicos derivados de embriões maduros, e obtiveram-se plantas transgênicas férteis, em menor espaço de tempo (Torbert et al., 1998). Contudo, esse explante também mostrou ser dependente do genótipo para o estabelecimento de culturas de calos embriogênicos e para regeneração de plantas. Apesar disso, as vantagens de utilizar esse explante torna de grande interesse a identificação de genótipos com capacidade embriogênica a partir dele.
Este trabalho teve por objetivo investigar o estabelecimento de calos embriogênicos e a regeneração de plantas, in vitro, de genótipos brasileiros de aveia, a partir de embriões maduros.

\section{Material e Métodos}

Os genótipos de aveia, UFRGS 7, UFRGS 14, UFRGS 19, UFRGS 930572 e UFRGS 930879-5, do Programa de Melhoramento Genético de Aveia da UFRGS, foram utilizados neste trabalho. As sementes desses genótipos foram obtidas de plantas cultivadas na Estação Experimental Agronômica (EEA - UFRGS), localizada em Eldorado do Sul, RS, em 1998. O processo de cultivo in vitro foi realizado no Laboratório de Cultura de Tecidos do Departamento de Plantas de Lavoura, da Faculdade de Agronomia, UFRGS

As sementes foram submetidas à desinfestação em etanol (EtOH) 70\%, durante três minutos, e, posteriormente, em hipoclorito de sódio $(\mathrm{NaOCl}$ ) 5\% (alvejante comercial, com concentração de 7 a $9 \%$ de cloro ativo), durante 20 minutos. Foram efetuadas cinco lavagens em água destilada estéril, em câmara de fluxo laminar.

Após a desinfestação, os genótipos permaneceram em solução fungicida de Baytan e de Thiram, nas dosagens de $1,6 \mathrm{~g} \mathrm{~L}^{-1} \mathrm{e} 2,0 \mathrm{~g} \mathrm{~L}^{-1}$, respectivamente, por quatro horas, em agitador orbital. Posteriormente, permaneceram em agitação por mais 20 horas em água destilada estéril, a fim de remover qualquer resíduo dos fungicidas, e eliminou-se a possibilidade de causarem algum dano fitotóxico às sementes. Passadas as 24 horas em agitação, foram efetuadas cinco lavagens com água destilada estéril.

Os embriões maduros foram retirados com o auxílio de lupa, bisturi e pinça esterilizados, em condições de assepsia, em câmara de fluxo laminar. Com auxílio do bisturi foi retirada a camada pilosa das sementes, e estas foram submetidas a um corte, para separar o endosperma do embrião. Os embriões foram colocados com o escutelo para baixo, em contato com meio de cultura (Figura 1A a 1C). Foram infectados 100 embriões por genótipo, com 10 embriões por placa, num total de 10 placas. As placas de Petri, contendo $50 \mathrm{~mL}$ de meio de cultura, foram fechadas com uma película de plástico, e identificadas.

O meio utilizado para cultura dos embriões foi o MS (Murashige \& Skoog, 1962), suplementado com 30,0 g L-1 de sacarose e $2,0 \mathrm{mg} \mathrm{L}^{-1}$ de 2,4-D (ácido 2,4-diclorofenoxiacético), $\mathrm{pH}$ ajustado para 5,8 e solidificado com 2,0 $\mathrm{g} \mathrm{L}^{-1}$ de Phytagel (Sigma Chemical CO). Os embriões foram incubados nas placas de Petri, por dois meses, na ausência de luz, e à temperatura de $22^{\circ} \pm 1^{\circ} \mathrm{C}$ (Figura 1D). Coleóptilos e raízes foram retirados, com o auxílio de te- 
soura, cinco dias após a infecção dos embriões. A partir de 60 dias de subcultivo, setores embriogênicos dos calos foram selecionados e subcultivados a cada 21 dias, em meio de cultura fresco. A análise da indução e multiplicação de calos embriogênicos foi realizada aos 60 e 123 dias, na ocasião dos subcultivos.
Os agregados embriogênicos selecionados foram transferidos para meio de diferenciação da parte aérea, onde permaneceram em presença de luz direta constante, e à temperatura de $22^{\circ} \pm 1^{\circ} \mathrm{C}$ (Figura 1E). O meio utilizado nessa etapa foi o MS, suplementado com 2,0 $\mathrm{mg} \mathrm{L}^{-1}$ de ANA (ácido $\alpha$-naftaleno acético) e $0,2 \mathrm{mg} \mathrm{L}^{-1} \mathrm{de}$

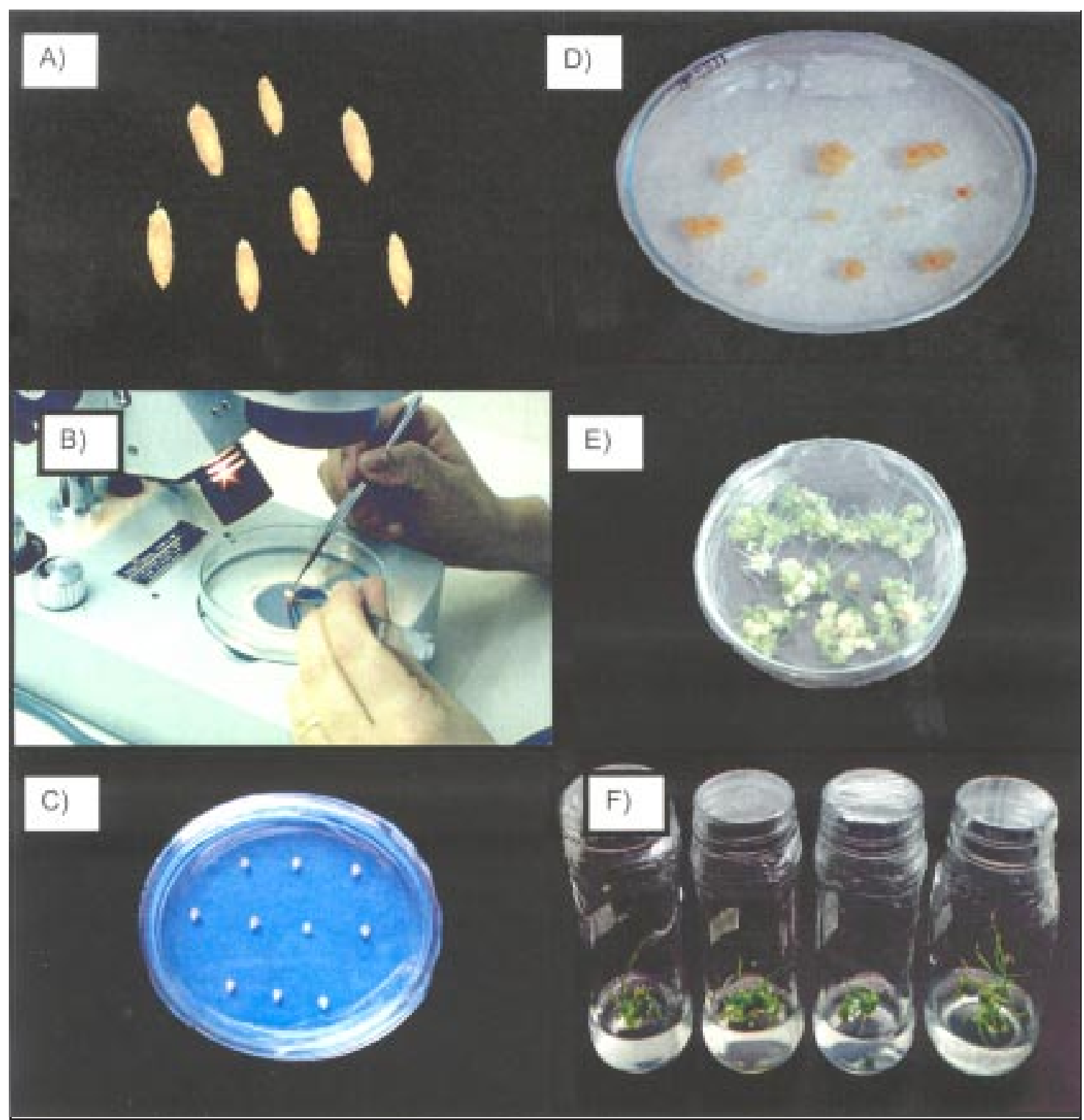

Figura 1. Seqüência de regeneração de plantas de aveia a partir de embriões maduros. A) sementes maduras de aveia; B) retirada de embriões maduros; C) embriões maduros em meio com 2,4-D; D) meio para indução de parte aérea com ANA (ácido $\alpha$-naftaleno acético) e BAP (6-benzilaminopurina); E) surgimento das primeiras folhas; F) meio de indução de raízes, sem reguladores de crescimento. 
BAP (6-benzilaminopurina). Após um mês em cultivo nesse meio, as partes aéreas foram passadas para meio de indução de raízes.

Frascos com capacidade de $250 \mathrm{~mL}$, contendo $40 \mathrm{~mL}$ de meio MS sem reguladores de crescimento, foram utilizados para regenerar raízes. As partes aéreas foram mantidas na presença de luz direta constante e à temperatura de $22^{\circ} \pm 1^{\circ} \mathrm{C}$ (Figura 1F); as que não induziram raízes foram descartadas. Esta etapa teve a duração de, aproximadamente, 30 dias, após os quais as plântulas passaram pelo período de aclimatização em vermiculita e em condições controladas em câmara de crescimento, para melhor adaptação.

Plântulas com sistema radicular formado tiveram suas raízes lavadas, para eliminar qualquer quantidade de resíduo do meio de cultura, e transferidas para copos de plástico de $250 \mathrm{~mL}$ contendo vermiculita estéril. Os copos permaneceram cobertos com película de PVC transparente, nas primeiras semanas, e a cada sete dias foram feitos orifícios, para adaptação gradativa da planta às condições ambientais. Essas plantas permaneceram na presença de luz, com temperatura de $22^{\circ} \pm 1^{\circ} \mathrm{C}$, por três semanas, em sala de crescimento, regadas com solução nutritiva. Após este período, foram transferidas para casa de vegetação, em potes de plástico com capacidade de $5 \mathrm{~kg}$ de substrato.

Os calos foram visualizados aos 60 dias de cultivo, com o auxílio de uma lupa, e foi registrada a porcentagem de calos embriogênicos, organogênicos e aquosos, pela contagem em cada placa de Petri. O número de agregados embriogênicos foi avaliado aos 60 e 123 dias, e, ao final do período de cultivo, o número de partes aéreas e plântulas por agregados embriogênicos. O número de embriões contabilizados no final variou entre os genótipos, devido a contaminações microbianas de embriões individuais ou placas inteiras.

Foi utilizado o delineamento completamente casualizado (DCC), considerando cada placa de Petri como unidade experimental. A análise de variância foi realizada quanto à embriogênese somática, à organogênese e a calos aquosos aos 60 dias, ao número de agregados embriogênicos por calo embriogênico aos 60 e 123 dias e ao número de partes aéreas e plântulas por agregados embriogênicos. Foi verificada a correlação entre o número de agregados embriogênicos e a regeneração de plântulas, no último dia de subcultivo de cada genótipo. Todas as análises foram feitas pelo programa estatístico Statistics Analysis System (SAS Institute, 1998). As médias dos genótipos foram comparadas pelo teste de Duncan, a 5\% de probabilidade. Foi realizada a transformação dos dados por $(\mathrm{x}+0,5)^{0,5}$, para obtenção da normalidade. No entanto, os valores apresentados nas Tabelas 1 e 2 são os originais.

\section{Resultados e Discussão}

Calos embriogênicos friáveis e de cor amarelada foram observados nos genótipos UFRGS 7, UFRGS 19 e UFRGS 930572. Nos genótipos UFRGS 14 e UFRGS 930879-5 não houve a individualização de setores nas fases de 60 e 123 dias, e estes apresentaram estruturas compactadas e nãofriáveis. Os calos organogênicos apresentaram aspecto esbranquiçado, com a formação de estruturas organizadas, como coleóptilos e raízes; os aquosos apresentaram-se totalmente translúcidos e líquidos (Figura 2), e ambos foram eliminados aos 60 dias. Essa identificação foi baseada no trabalho de Bregitzer et al. (1989), que fizeram a caracterização de calos friáveis e não-friáveis derivados de embriões imaturos de aveia.

Aos 60 dias de subcultivo não houve diferenças significativas entre os genótipos nos calos embriogênicos e aquosos, mas as diferenças apareceram nos calos organogênicos (Tabela 1). A maior parte dos calos foi de aparência aquosa; um pequeno número de embriogênicos e os genótipos UFRGS 7 e UFRGS 930879-5 apresentaram calos organogênicos aos 60 dias (Tabela 1, Figura 2). Apesar de a regeneração de plantas ser possível via embriogênese ou organogênese, atualmente os esforços estão concentrados na regeneração de plantas, a partir de embriões somáticos. Esses embriões têm estrutura bipolar característica, cujos ápices caulinares e radiculares são conectados diretamente. Ao contrário, quando brotos e raízes são formados de calos via organogênese, esses ocorrem de forma independente, em relação ao tempo e à localização (Lörz et al., 1988).

Tabela 1. Porcentagem média de calos embriogênicos, organogênicos e aquosos avaliados aos 60 dias de subcultivo, em cinco genótipos de aveia ${ }^{(1)}$

\begin{tabular}{lccc}
\hline Genótipo & Embriogênicos & Organogênicos & Aquosos \\
\hline UFRGS 7 & $6 \mathrm{a}$ & $11 \mathrm{a}$ & $64 \mathrm{a}$ \\
UFRGS 14 & $1 \mathrm{a}$ & $0 \mathrm{~b}$ & $89 \mathrm{a}$ \\
UFRGS 19 & $2 \mathrm{a}$ & $0 \mathrm{~b}$ & $98 \mathrm{a}$ \\
UFRGS 930572 & $1 \mathrm{a}$ & $0 \mathrm{~b}$ & $84 \mathrm{a}$ \\
UFRGS 930879-5 & $1 \mathrm{a}$ & $12 \mathrm{a}$ & $81 \mathrm{a}$ \\
\hline CV (\%) & 17,5 & 16,5 & 14,6 \\
\hline
\end{tabular}

(1)Médias seguidas pela mesma letra não diferem entre si, pelo teste de Duncan a 5\% de probabilidade. 
Apesar de não haver diferença significativa entre genótipos aos 60 dias na freqüência de calos embriogênicos, foram descartados os calos que não apresentavam agregados embriogênicos neste período. Diferenças significativas entre genótipos teriam sido detectadas se todos os calos tivessem sido mantidos em cultivo por um período mais longo. Na prática, contudo, a seleção de calos embriogênicos é feita aos 60 dias, porque a manutenção de um excessivo número de calos não diferenciados a cada subcultivo torna-se trabalhosa para a rotina de um laboratório. Assim, neste trabalho optou-se por avaliar a capacidade multiplicativa dos calos embriogênicos após os 60 dias, pela contagem dos agregados embriogênicos no decorrer dos subcultivos subseqüentes.

Segundo Emons (1994), a embriogênese é definida como o desenvolvimento de células somáticas que permitem a histodiferenciação, resultando em estruturas semelhantes a embriões zigóticos. No presente trabalho foi possível identificar embriões zigóticos, e os calos embriogênicos apresentavam intensa multiplicação celular e friabilidade em alguns genótipos. Houve diferença significativa no número de agregados embriogênicos produzidos por calo pelos genótipos aos 123 dias, mas não aos 60 dias (Tabela 2). Os genótipos UFRGS 19e UFRGS 930879-5 foram os que apresentaram, respectivamente, o maior e o menor número médio de agregados embriogênicos por calo, nesse período. Para Rines \& McCoy (1981) e Bered et al. $(1996,1998)$, a qualidade de estabelecimento em cultura de tecidos depende do genótipo, fator esse que também foi verificado neste trabalho na indução de parte aérea e regeneração de plântulas (Tabela 3).
Os genótipos UFRGS 7, UFRGS 19 e UFRGS 930879-5 produziram consistentemente alta frequiência de culturas de calos embriogênicos regeneráveis (Tabela 3 ). O genótipo UFRGS 930879-5, apesar de não ter apresentado superioridade em relação à indução de calos embriogênicos, foi superior em número de partes aéreas e em plântulas por agregados embriogênicos (Tabela 3). A diferenciação de calos na parte aérea inicia-se com os primeiros sinais de organização, em que ocorre a formação de pequenas estruturas verdes. Os genótipos UFRGS 930572 e UFRGS 14 não produziram parte aérea, e portanto, foram descartados nesta fase. Apesar de seu potencial de produção de um alto número de partes aéreas por agregados embriogênicos, as plântulas do genótipo UFRGS 930572 tenderam a desenvolver raízes amareladas e frágeis. Após aproximadamente três semanas, quando o sistema radicular estava bem desenvolvido, as plântulas foram para o período de aclimatização, e transferidas para casa de vegetação (Figura 3). O genótipo UFRGS 7 confirmou sua potencialidade no cultivo in vitro com o uso de embriões maduros, visto que já se havia destacado em capacidade embriogênica e de regeneração de plantas em trabalhos anteriores, a partir de embriões imaturos (Bered et al., 1996, 1998)

Neste trabalho, o tempo entre a retirada de embriões de sementes maduras até a regeneração de uma planta completa, in vitro, de aveia, foi aproximadamente, de sete meses. Na regeneração de plantas in vitro, muitas vezes faz-se necessária a permanência em meio de cultura por várias semanas, ou até mesmo anos. Um período de um ano e meio foi relatado por Cummings et al. (1976) para obtenção de

Tabela 2. Número de embriões maduros, porcentagem de calos embriogênicos e número de agregados embriogênicos por calo em cinco genótipos de aveia ${ }^{(1)}$

\begin{tabular}{|c|c|c|c|c|c|}
\hline \multirow[t]{2}{*}{ Genótipo } & \multirow{2}{*}{$\begin{array}{l}\text { Embriões } \\
\text { maduros } \\
\left(\mathrm{n}^{\circ}\right)\end{array}$} & \multicolumn{2}{|c|}{$\begin{array}{l}\text { Calos embriogênicos } \\
\text { aos } 60 \text { dias }\end{array}$} & \multicolumn{2}{|c|}{$\begin{array}{l}\text { Número de agregados } \\
\text { embriogênicos/calo }\end{array}$} \\
\hline & & $\left(n^{o}\right)$ & $(\%)$ & 60 dias & 123 dias \\
\hline UFRGS 7 & 90 & 5 & 5,5 & $2,3 a$ & $63,0 \mathrm{ab}$ \\
\hline UFRGS 14 & 91 & 1 & 1,0 & $1,0 \mathrm{a}$ & $7,0 \mathrm{bc}$ \\
\hline UFRGS 19 & 100 & 2 & 2,0 & $2,5 \mathrm{a}$ & $89,5 \mathrm{a}$ \\
\hline UFRGS 930572 & 85 & 1 & 1,2 & $2,0 \mathrm{a}$ & $38,9 \mathrm{ab}$ \\
\hline UFRGS 930879-5 & 100 & 1 & 1,0 & $1,0 \mathrm{a}$ & $1,0 \mathrm{c}$ \\
\hline
\end{tabular}

${ }^{(1)}$ Médias seguidas de mesma letra não diferem entre si, pelo teste de Duncan a $5 \%$ de probabilidade 
regenerantes a partir de embriões imaturos, em aveia. Desta forma, com o uso de embriões maduros foi possível reduzir pela metade o tempo de cultivo in vitro, semelhante ao que foi relatado por Torbert et al. (1998)
Embora a dificuldade da aveia de regenerar raízes in vitro seja um fato conhecido (Bered et al., 1998), a regeneração ocorreu com sucesso em alguns genótipos avaliados, e um grande número de plântulas foi obtido (Tabela 3, Figura 3).

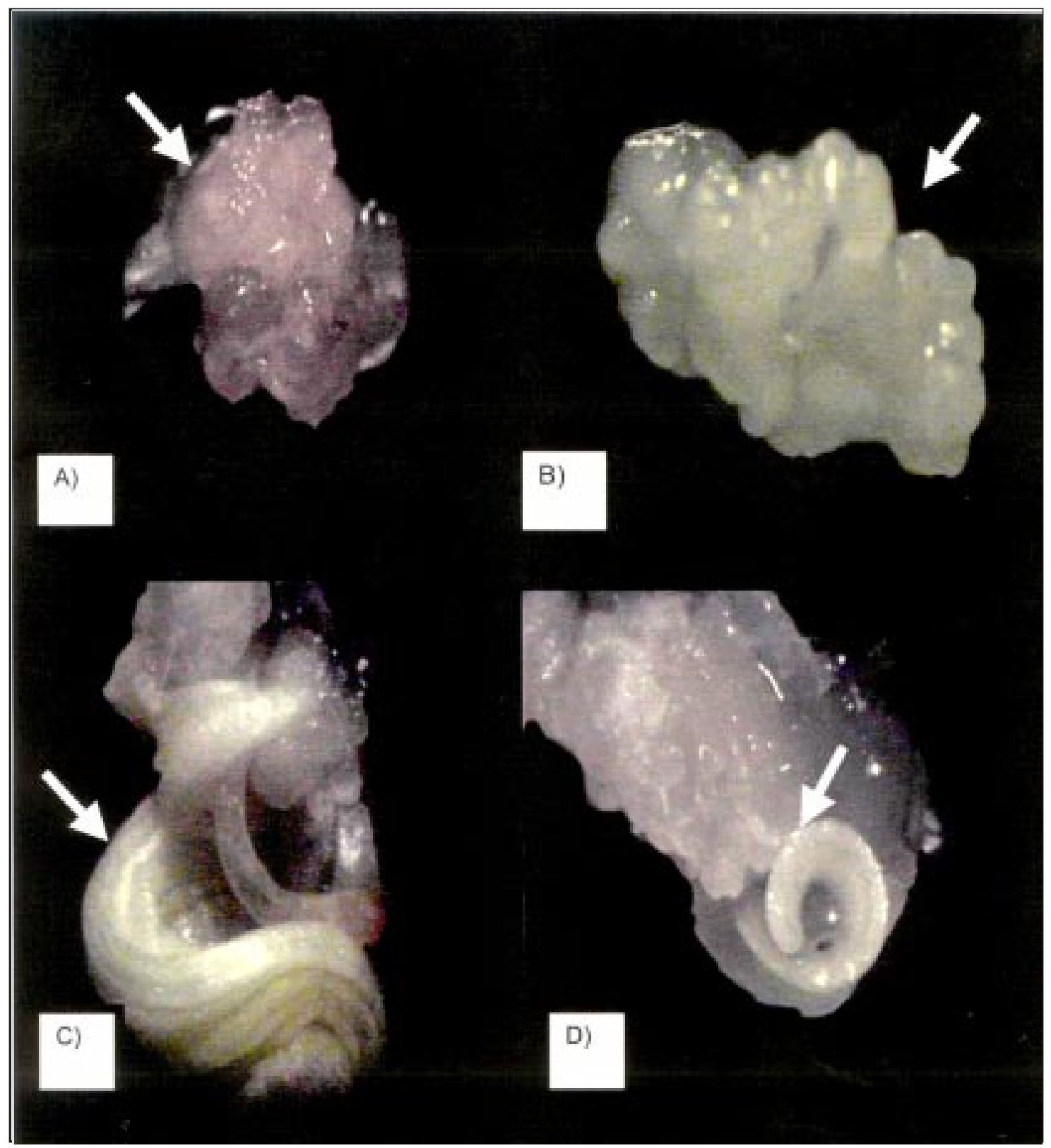

Figura 2. Tipos de calos obtidos em UFRGS 7. As setas indicam: A) calo aquoso; B) calo embriogênico; C) calo organogênico; D) calo misto. 
Tabela 3. Número de agregados embriogênicos, número de partes aéreas regeneradas e de partes aéreas por agregado embriogênico, número total de plantas e de plantas por agregado embriogênico, e coeficientes de correlação entre o número de agregados embriogênicos e de plântulas regeneradas, em cinco genótipos de $\operatorname{aveia}^{(1)}$.

\begin{tabular}{lcccccc}
\hline Genótipo & $\begin{array}{c}\text { Agregados } \\
\text { embriogênicos }\end{array}$ & $\begin{array}{c}\text { Partes aéreas } \\
\text { regeneradas }\end{array}$ & $\begin{array}{c}\text { Partes aéreas por } \\
\text { agregado embriogênico }\end{array}$ & $\begin{array}{c}\text { Total de } \\
\text { plantas }\end{array}$ & $\begin{array}{c}\text { Plantas por agregado } \\
\text { embriogênico }\end{array}$ & $\begin{array}{c}\text { Coeficiente de } \\
\text { correlação }\end{array}$ \\
\hline UFRGS 7 & 251 & 87 & $0,35 \mathrm{~b}$ & 109 & $0,43 \mathrm{~b}$ & 0,80 \\
UFRGS 14 & 13 & 0 & $0,00 \mathrm{~b}$ & 0 & $0,00 \mathrm{~b}$ & 0,00 \\
UFRGS 19 & 329 & 277 & $0,84 \mathrm{~b}$ & 200 & $0,61 \mathrm{~b}$ & 0,86 \\
UFRGS 930572 & 73 & 0 & $0,00 \mathrm{~b}$ & 0 & $0,00 \mathrm{~b}$ & 0,00 \\
UFRGS 930879-5 & 3 & 18 & $6,00 \mathrm{a}$ & 13 & $4,33 \mathrm{a}$ & 1,00 \\
\hline
\end{tabular}

${ }^{(1)}$ Médias seguidas pela mesma letra não diferem entre si, pelo teste de Duncan a $5 \%$ de probabilidade.

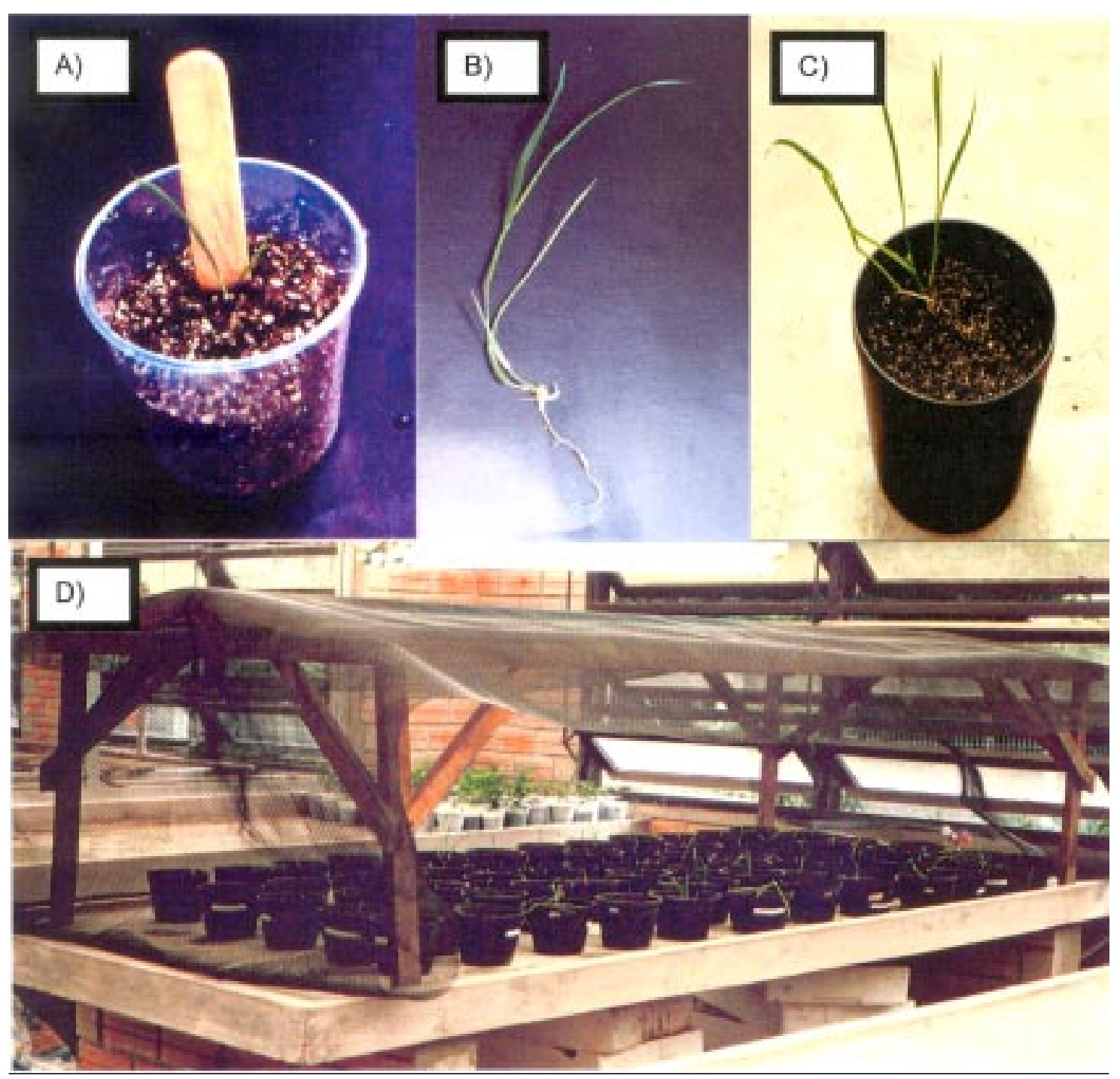

Figura 3. A) Período de aclimatização em vermiculita; B) plântula completa com raiz e parte aérea; C) plântulas em substrato em casa de vegetação; D) panorama geral das plantas em casa de vegetação. 
Alta correlação foi observada entre a embriogênese e a regeneração de plântulas (Tabela 3), o que permite inferir que a regeneração ocorreu a partir da embriogênese somática. Segundo Bhaskaran \& Smith (1990), as plantas que regeneram a partir de embriões são preferidas, por possuírem maior integridade genética.

\section{Conclusões}

1. Existe variabilidade entre os genótipos de aveia testados, quanto à capacidade de embriogênese somática e quanto à regeneração de plantas in vitro a partir de embriões maduros.

2. A variabilidade entre os genótipos de aveia testados só se torna evidente 123 dias após o início do seu cultivo.

3. O embrião maduro permite a indução de calos embriogênicos, que se multiplicam, e que regeneram in vitro um grande número de plantas de aveia.

\section{Agradecimentos}

À Fapergs, pelo apoio financeiro e bolsa de iniciação científica para o desenvolvimento deste trabalho; ao CNPq, pela bolsa de mestrado concedida ao primeiro autor.

\section{Referências}

BERED, F.; SERENO, M. J. C. de M.; CARVALHO, F. I. F. de; FEDERIZZI, L. C.; DORNELLES, A. L. C.; LANGE, C. E.; HANDEL, C. L. Avaliação de embriogênese somática em cultivares de aveia (Avena sativa L.). Ciência Rural, Santa Maria, v. 26, n. 3, p. 371$375,1996$.

BERED, F.; SERENO, M. J. C. de M.; CARVALHO, F. I. F. de; LANGE, C. E.; HANDEL, C. L.; DORNELLES, A L. C. Regeneração de plantas de aveia a partir de calos embriogênicos e organogênicos. Pesquisa Agropecuária Brasileira, Brasília, v. 33, n. 11, p. 1827-1833, nov. 1998

BHASKARAN, S.; SMITH, R. H. Regeneration in cereal tissue culture: A review. Crop Science, Madison, v. 30, p. 1328-1336, 1990.
BREGITZER, P. P.; MILACH, S. C. K.; RINES, H. W. SOMERS, D. A. Somatic embryogenesis in oat (Avena sativa L.). In: BAJAJ, Y. P. S. (Ed.). Biotechnology in agriculture and forestry. (Ed.). New York: Springer, 1995. p. $53-62$.

BREGITZER, P. P.; SOMERS, D. A.; RINES, H. W. Development and characterization of friable, embryogenic oat callus. Crop Science, Madison, v. 29, p. 798-803, 1989.

CARTER, O.; YAMADA, Y; TAKAHASHI, E. Tissue culture of oats. Nature, London, v. 241, n. 3, p. 1029-1030, 1967.

CUMMINGS, D. P.; GREEN, C. E.; STUTHMAN, D. D. Callus induction and regeneration in oats. Crop Science, Madison, v. 16, p. 465-470, 1976.

EMONS,A. M. C. Somatic embryogenesis: cell biological aspects. Acta Botanical Neerlandica, Stuttgart, v. 41, n. 1, p. 1-14, 1994.

HANDEL, C. L.; WAGNER, C. M.; MILACH, S. C. K.; FEDERIZZI, L. C. Transformação genética de cereais via Agrobacterium tumefaciens. Ciência Rural, Santa Maria, v. 27, n. 2 , p. $359-365,1997$.

LÖRZ, H.; GÖBEL, E.; BROWN, P. Advances in tissue cultures and progress towards genetic transformation of cereals. Plant Breeding, Berlin, v. 100, p. 1-25, 1988.

MURASHIGE, T.; SKOOG, F. A revised medium for rapid growth bioassay with tobacco tissue cultures. Physiologia Plantarum, Copenhagen, v. 15, p. 473-497, 1962.

RINES, H. W.; McCOY, T. J. Tissue culture initiation and plant regeneration in hexaploid species of oats. Crop Science, Madison, v. 21, p. 837-842, 1981.

SAS INSTITUTE (Cary, Estados Unidos). SAS user's guide. Cary, 1998. $521 \mathrm{p}$.

SOMERS, D. A.; RINES, H. W.; TORBERT, K. A.; MILACH, S. C. K. Genetic transformation in Avena sativa L. In: BAJAJ, Y. P. S. (Ed.). Biotechnology in agriculture and forestry. New York: Springer, 1996. p. $178-190$

TORBERT, K. A.; RINES, H. W.; SOMERS, D. A. Transformation of oat using mature embryo-derived tissue cultures. Crop Science, Madison, v. 38, p. 226-231, 1998. 